\title{
Persistencia de una escuela rudimentaria en una comunidad zapoteca del sur de Oaxaca (1930-1965)
}

The Persistence of a Rudimentary School in a Zapotec Community in Southern Oaxaca (1930-1965)

\section{Edgar Pérez Ríos}

Departamento de Investigaciones Educativas del Cinvestav edgarperezrios@gmail.com

\begin{abstract}
Resumen
Aunque se supone que, como proyecto educativo del Estado, las escuelas rudimentarias fueron reemplazadas por la escuela rural mexicana en la década de los veinte del siglo pasado, en este artículo muestro el caso de una comunidad zapoteca de la Sierra Sur de Oaxaca donde la escuela rudimentaria persistió hasta 1965, año en que se instauró una escuela rural federal. La metodología empleada para este estudio se basa en una etnografía histórica, al ser la historia oral la principal herramienta para obtener la información que aquí presentamos, ya que al tratarse de un caso aparentemente al margen de la educación nacional, la documentación al respecto es prácticamente inexistente. La conclusión que deriva de este trabajo es que la persistencia de la escuela rudimentaria se debió al desinterés del Estado en regiones poco atractivas para la anhelada modernización del país y a la forma de vida tradicional de la comunidad con base en su territorialidad sagrada.
\end{abstract}

Palabras clave: educación rudimentaria, educación rural, educación indígena, territorialidad sagrada, Oaxaca.

\section{Abstract}

It is normally assumed that the early state-run rudimentary schools were replaced in the 1920s by the so-called Mexican rural schools. However, as this article shows, in the case of a Zapotec community in the South Sierra of Oaxaca, a federal rural school was not established until 1965. Documentation regarding this case is practically nonexistent because the school survived in the margins of the national education system. The methodology used is historical ethnography, relying mainly on information 
obtained from oral history provided by local informants. The conclusion is that the persistence of the rudimentary school was due to two factors: first, the lack of interest of State authorities in regions considered unattractive for the desired national modernization; second, the community's traditional way of life based on sacred territory.

Keywords: rudimentary education, rural education, indigenous education, sacred territory, Oaxaca.

\section{Introducción}

Las escuelas rudimentarias forman parte de un proyecto del gobierno mexicano en el naciente siglo XX, contexto en el que según datos del Censo General de Población y Vivienda de 1910, 88\% de la población era rural y el analfabetismo ascendía aproximadamente a 80\% (cit. en Pani, 1912). Situación contradictoria para los planes de modernización del gobierno en turno el cual "se caracterizó por una cuantiosa inversión extranjera directa, primordialmente en la minería, el petróleo y la agricultura de haciendas, así como de préstamos para la expansión de los ferrocarriles y el telégrafo" (Roett, 1999: 45).

Además del referido analfabetismo, las autoridades de la época consideraban que los pueblos indígenas constituían un obstáculo para los planes de modernización del país. En 1895 en Oaxaca, por ejemplo, la población indígena representaba 78\%, mientras que en 1930 las cifras no habían cambiado mucho, ya que para entonces se registraba un monolingüismo en lengua indígena de 60\% (INEGI, 2004). Aunque los criterios para designar a la población indígena no necesariamente son confiables, las estadísticas permiten tener una idea más o menos general sobre esta cuestión en aquella época.

La situación indígena tampoco pasaba desapercibida para las autoridades educativas como Justo Sierra, director de la entonces Secretaría de Instrucción Pública y Bellas Artes, quien en el marco del III Congreso de Educación Primaria de 1910, centrado en la modernización de la educación, mencionaba que "'un inmenso número' de mexicanos estaba 'privado de todo contacto con el alma nacional' a causa del aislamiento, la miseria, el predominio de la superstición y el alcoholismo. Sierra hacía un llamado urgente a 'modificar profundamente' esa situación a la vuelta de dos generaciones" (Granja, 2010: 71). Bajo las ideas de modernización se comenzaron a gestar las escuelas rudimentarias, ya que, de acuerdo con Sierra, con esta estrategia sería posible "hacernos de esa parte de los espíritus de nuestra nación que ni habla nuestro idioma ni tiene nuestras costumbres".

\footnotetext{
${ }^{1}$ Congreso Nacional de Educación Primaria, Tipografía económica, México, 1911, p. 26.
} 
De manera paralela a los proyectos educativos de 1910 se daba un tenso clima político que culminó en la caída del régimen porfirista en 1911, quedando como presidente interino Francisco León de la Barra, y al frente de la Secretaría de Instrucción Pública Jorge Vera Estañol (Meneses, 1998). En ese tenor continuaba adelante la iniciativa de ley para instaurar escuelas rudimentarias en el país, misma que fue aprobada en junio de 1911 durante el interinato de León de la Barra. Los puntos principales eran que las escuelas se dirigieran principalmente a población indígena, con el fin de enseñarle a hablar, leer y escribir el castellano, así como las operaciones matemáticas básicas. "La duración sería de dos cursos anuales, careciendo de obligatoriedad" (Granja, 2010: 72). No obstante, el curso de dos años no era el límite establecido para los alumnos, sino que "una vez concluido se abrían nuevas posibilidades, se implementaban también con la idea de que los alumnos destacados pudieran pasar a las primarias regulares" (Solana, 2006: 247).

Así, en 1911 comenzaron a operar las primeras escuelas rudimentarias no sin fuertes críticas por parte de intelectuales de la época, como Alberto Pani (1912) y Ezequiel Chávez quienes también habían ocupado cargos dentro de la Secretaría de Instrucción Pública. No obstante, personas como Justo Sierra y Grogorio Torres Quintero -este último como jefe de la Sección de Instrucción Primaria y Normal- defendían la continuidad del proyecto: "Una escuela rudimentaria con su programa de leer, escribir y contar puede ser completa con relación a cierto estado social y coadyuvar al progreso de las congregaciones humanas correspondientes [...] Lo que es una educación completa para un niño esquimal puede ser rudimentaria para un niño de París" (Quintero, 1913: 9). Pani (1912: 20-21), por su parte, argumentaba que

\footnotetext{
[...] la débil acción educadora de las escuelas rudimentarias a causa del carácter puramente abstracto de las enseñanzas que pretende impartir dichas escuelas, pudiendo resultar la labor de éstas, por efecto de dicho carácter abstracto de la enseñanza, inútil o nociva. [...] los conocimientos abstractos rudimentarios allí difundidos no pueden tener una aplicación práctica inmediata -olvidándolos tanto más pronto cuanto más deficiente ha sido su enseñanza y resultando entonces inútil la gestión escolar.
}

Lo cierto es que, como he señalado en otro texto, "desde la creación de las escuelas rudimentarias en 1911 se comenzaba un proyecto con más probabilidades de fracaso que de triunfo" (Pérez, 2014: 117). Al respecto, Ernesto Meneses subraya las causas de que las escuelas rudimentarias terminaran aboliéndose pocos años después de su creación; se resumen en la precariedad del modelo, la insuficiencia de los recursos tanto económicos como humanos, incluso pedagógicos, además de la escasa importancia de este modelo para los pueblos originarios, principales destinatarios del proyecto: "[...] la estrechez económica de los cam- 
pesinos, su apatía e indolencia respecto a la propia convivencia, trabajo de los niños en la siembra, la cosecha y cuidado de los animales, poco atractivo de la escuela más parecida a un cuartel o prisión, la condición de los maestros que desconocían el medio [...]" (Meneses, 1998: 231).

Así pues, esta escuela distante de las realidades indígenas no prosperó, de manera que "el ciclo de vida de las escuelas rudimentarias se cierra con la Casa del Pueblo, como esbozo de la nueva escuela rural posrevolucionaria" (Granja, 2010: 65), conservando su objetivo principal, es decir, la castellanización y homogeneización cultural. A pesar de que en la década de 1920 se crearon proyectos educativos nacionales, tales como la escuela rural mexicana, las casas del pueblo, la casa del estudiante indígena y posteriormente, hacia mediados de ese siglo, la escuela socialista y la escuela de la unidad nacional. En varias comunidades indígenas persistieron las escuelas rudimentarias como documentan Kraemer (2003) y Sigüenza (2015) en la Sierra Norte de Oaxaca y como he observado en Soledad Piedra Larga (SPL), una comunidad zapoteca de la Sierra Sur del mismo estado donde hubo una escuela rudimentaria hasta 1965. Pero, ¿por qué persistió este modelo educativo en esta comunidad? ¿Cuál era el contexto local en SPL en relación con la escuela? En las siguientes páginas analizo este caso particular en un intento de responder estas preguntas. Comienzo describiendo el proceso metodológico que orienta este estudio, posteriormente ofrezco un breve panorama etnohistórico de la comunidad en cuestión para luego arribar al tema central del artículo: la persistencia de la escuela rudimentaria. Particularmente me interesa discutir dos hipótesis: por una parte que Soledad Piedra Larga no fue contemplado dentro de los llamados experimentos sociales del estado (Calderón, 2018), dado que no ofrecía ningún atractivo socioeconómico ni productivo dentro del proyecto de modernización del estado, además de que a la población de SPL tampoco le interesaba relacionarse con la sociedad nacional debido al fuerte vínculo con su territorio instrumental y sagrado (Barabás, 2004), mismo que les brindaba todo lo necesario para la vida. Aunado a esto se pretende visibilizar la capacidad de agencia de esta localidad en su devenir histórico como pueblo originario anclado a un territorio específico.

\section{Proceso metodológico}

Este artículo se desprende de una investigación más amplia correspondiente al doctorado en Investigaciones Educativas en el Departamento de Investigaciones Educativas del Centro de Investigación y de Estudios Avanzados del Instituto Politécnico Nacional (DIE-Cinvestav) -bajo la asesoría de las doctoras Antonia Candela y Gabriela Czarny- donde se documentan procesos de reconfiguración sociocultural y lingüística en el municipio de San Je- 
rónimo Coatlán (SJC), Oaxaca, municipio al que pertenece la comunidad de Soledad Piedra Larga. ${ }^{2}$

Planteo un enfoque de investigación a partir de lo que Rockwell (2007a) señala como etnografía histórica, donde las fuentes, archivos y documentos históricos y la propia historia oral permiten comprender dinámicas escolares actuales cuya explicación se encuentra en un proceso de larga data. En ese sentido el presente estaría lleno de huellas del pasado. Este acercamiento etnográfico e histórico lo he fortalecido mediante lo que denomino metodología comunal, es decir, mediante un acercamiento metodológico decolonial centrado en la co-construcción de conocimientos y compartencia de los mismos con otros miembros de la comunidad (ver Pérez, 2018b). Cabe señalar que la compartencia es una perspectiva surgida desde la comunalidad oaxaqueña propuesta por Martínez (2010), la cual se contrapone al concepto de competencia, entendiendo ésta como una lógica económica capitalista, mientras que aquella responde a una naturaleza colectiva. En este sentido los saberes son colectivos y la compartencia es el modo en que se socializan.

Así pues, "con la co-construcción de conocimientos con otros miembros de la comunidad me refiero a un proceso reflexivo donde discutimos de manera colegiada algún tema en particular en algún espacio determinado" (Pérez, 2018b: 149). Así, el tema que aquí nos ocupa y los resultados que más adelante se discuten son producto no sólo de una reflexión personal sino también de diversas reflexiones conjuntas en distintos espacios donde las pláticas a la orilla de la calle, en alguna fiesta comunitaria, incluso degustando de un mezcal sustituyeron las entrevistas formales. Esta forma de co-construcción de conocimientos también la he desarrollado a través de talleres comunitarios, como una forma de descolonización del saber (Santos, 2010), con la participación de jóvenes y adultos. Al final de la jornada la información y reflexiones quedaron anotadas en el diario de campo; algunos fragmentos de dicho diario aparecen citados en este texto.

La herramienta principal para recabar información respecto a la escuela en SPL ha sido a través de la historia oral, misma que tomo como fuente legítima de construcción de conocimientos históricos y que a la vez constituye un esfuerzo por "democratizar el quehacer histórico" (Portelli, 1991: 29). Sin entrar en una discusión sobre una posible disyuntiva entre historia oral y la Historia, aquí vale la pena señalar que utilizo la perspectiva oral en tanto "una herramienta de fácil manejo, cuyo empleo se aprende al mismo tiempo que se producen resultados. Estos resultados recalcan la diversidad de la experiencia humana en cualquier contexto" (Necoechea, 1996: 82). También se recurrió al Archivo de Bienes Comunales de San Jerónimo Coatlán (ABCSJC) y al Archivo General de la Nación (AGN) para recabar datos sobre aspectos etnohistóricos de la población aquí referida.

\footnotetext{
${ }^{2}$ De donde también es originario el autor.
} 
Finalmente, los testimonios orales que se retoman en este artículo corresponden en su mayoría a adultos mayores, hombres y mujeres, nacidos en Soledad Piedra Larga en las décadas de 1930 y 1940, pues ellos suelen recordar de voz de sus padres el proceso fundacional de esta comunidad, ocurrido posiblemente entre 1930 y 1932. También se recuperan testimonios de adultos nacidos entre 1950 y 1960, dado que ellos vivieron la transición entre la escuela rudimentaria y la escuela federal; en ese sentido cito nombres reales cuando el testimonio alude a información personal. Cuando se trata de información regularmente compartida entre distintos miembros de la comunidad se omiten los nombres propios y se hace una generalización.

\section{Breve panorama etnohistórico de Soledad Piedra Larga}

Se sabe que cuando los españoles llegaron a la Sierra Sur de Oaxaca, Coatlán abarcaba un extenso territorio que se extendía desde el corazón de la Sierra Sur hasta las costas de Oaxaca. El sistema político centralizado en Coatlán se fortalecía mediante alianzas con otros señoríos incluso lingüísticamente diferenciados, como es el caso de los mixtecos de Tututepec — alianzas que se hacían mediante enlaces matrimoniales (Rosas, 2016) - . Sin embargo, tras la conquista el pueblo de Coatlán quedó desarticulado y pese a las insurrecciones y revueltas que protagonizaron sus pobladores durante gran parte del siglo XVI con el objetivo de restablecer el antiguo orden ${ }^{3}$ nunca lograron su cometido. De esta manera, posiblemente hacia finales del siglo XVI, la población se dispersó dando pie a la fundación de nuevos pueblos, entre ellos San Jerónimo Coatlán.

Basilio Rojas (1958) sostiene que sjc se fundó en 1612, luego de una larga peregrinación, situación que también se manifiesta en el lienzo de San Jerónimo Coatlán, elaborado posiblemente a principios del siglo XVII, ${ }^{4}$ y que se reafirma en la historia oral que aún se transmite en este municipio. La historia oral refiere que, una vez establecidos, se ordenó una comisión de hombres para que marcaran sus límites territoriales. Así, fueron colocadas las mojoneras en los límites con la región chatina, la costa y otros pueblos zapotecos como se observa en el Mapa de San Jerónimo Coatlán de 1690,5 para cubrir hasta la actualidad una extensión territorial de 558 km² (INEGI, 2010).

Precisamente en el extremo colindante con la región chatina se avecinaron centenas de pobladores de SJC, quienes vivían en pequeñas rancherías distribuidas por el amplio territo-

\footnotetext{
${ }^{3}$ AGN, Inquisición, vol. 37, exp. 9

${ }^{4}$ ABCSJC, carpeta 1 .

${ }^{5}$ lbid., carpeta 2.
} 
rio; así, según el Censo General de Población y Vivienda (1900) en estas rancherías vivían 522 personas mientras que en el pueblo de San Jerónimo Coatlán vivían solamente 184. De acuerdo con la información de los abuelos, hacia 1930 los pobladores de las rancherías, quienes habitaban el lugar desde hacía por lo menos 300 años, decidieron formar un nuevo pueblo, pues hasta entonces tenían que prestar los servicios comunitarios bajo el sistema de cargos en el pueblo de SJC, alejado de sus rancherías por lo menos un día de camino. Cabe destacar que para entonces toda la población era hablante del idioma di zhke' o zapoteco coateco, con presencia de un bilingüismo incipiente.

Según los relatos orales de los abuelos, entre 1930 y 1932 - no sin una serie de graves conflictos - lograron fundar el nuevo pueblo al cual Ilamaron Soledad Piedra Larga, en honor a una piedra prehispánica de uso ritual (llamada gué sant en zapoteco, traducido como "piedra santa") que aún permanece en las afuera de la localidad (ver Pérez, 2019b). Este hecho es crucial para comprender las distintas dinámicas que se gestaron a partir de entonces, quizá la más trascendente es que desde entonces los pobladores de SPL decidieron -incluso probablemente mediante Asamblea - dejar de hablar el di'zhke', su idioma originario y hasta ese momento la lengua materna, contrario a los habitantes de sJc, que continuaron hablando el zapoteco coateco al menos durante dos generaciones más. La decisión de tomar la castilla como primera lengua al parecer fue una decisión irreversible, pues en la actualidad es el idioma que se habla en dicha comunidad, además de mostrar una capacidad de agencia indígena en relación con el uso de las lenguas.

Cabe destacar que en el caso de SPL la adopción del castellano sucedió en un contexto donde los elementos actualmente asociados al desplazamiento lingüístico tales como la escuela, la discriminación, la migración, entre otros, no estaban presentes en esta localidad, lo cual se documenta a profundidad en Pérez (2018a). Además, en 1930, 60\% de la población en Oaxaca únicamente hablaba su lengua originaria (INEGI, 2004). Lo que podría explicar este fenómeno sociolingüístico más bien se asocia a un conflicto intra-étnico entre los pobladores de San Jerónimo Coatlán y Soledad Piedra Larga, lo cual derivó en una separación no sólo territorial sino también lingüística.

Una de las estrategias que utilizaron los pobladores de SPL para hacerse de la castilla en el plano de la lectura y escritura y para fortalecer la oralidad fue justamente la fundación de una escuela; es decir, instauraron la escuela como un proyecto comunitario y no como un proyecto del Estado. También es necesario señalar que estas nuevas dinámicas lingüísticas no afectaron la relación sagrada con el territorio, sus sistemas rituales (agrícolas, fúnebres, de paso, etc.), pues adaptaron el español a este mundo simbólico, de tal suerte que todo lo comenzaron a nombrar con el nuevo idioma, haciendo traducciones literales y zapotequizando el español (Pérez, 2018a; Pérez, 2019b). 
Actualmente Soledad Piedra Larga, situado a 1000 msnm, ostenta la categoría política de agencia municipal, ubicado como ya se anticipó en el municipio de San Jerónimo Coatlán, distrito de Miahuatlán, en la región de la Sierra Sur de Oaxaca. De acuerdo con el padrón de comuneros su población es aproximadamente 1000 habitantes, de los cuales — se identificó en trabajo de campo - sólo una docena — todos mayores de 70 años - son recordadores del idioma originario, es decir, no hablan zapoteco pero son capaces de recordar algunas palabras. Los habitantes de Soledad Piedra Larga son parte del pueblo zapoteco, el cual es uno de los 16 pueblos originarios en el estado de Oaxaca.

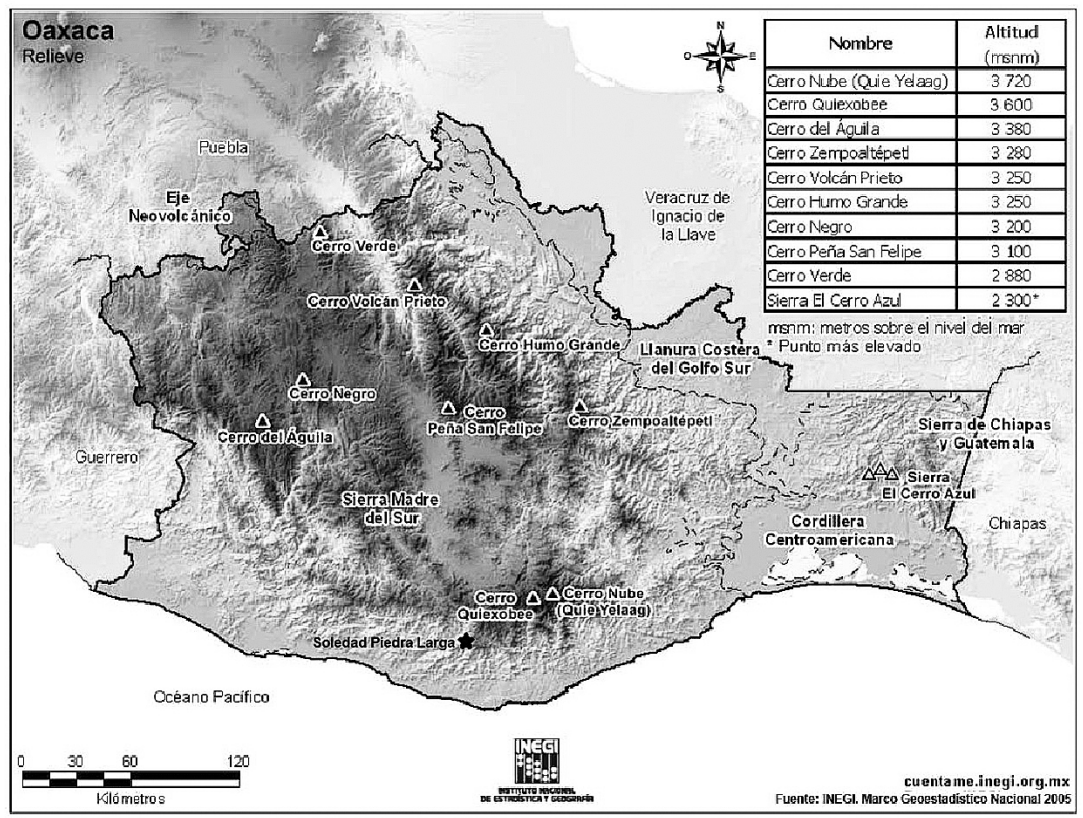

Mapa I. Ubicación de Soledad Piedra Larga, en la Sierra Sur del estado de Oaxaca, modificado de www.cuentame.inegi.org.mx

\section{Construcción del territorio sagrado en Soledad Piedra Larga}

Antes de pasar propiamente a la experiencia de las escuelas rudimentarias es pertinente contextualizar el territorio sagrado de SPL, pues uno de mis argumentos es que este territorio permitió una forma de vida aparentemente aislada de la sociedad nacional a pesar de la 
adopción del castellano el cual, como se ha señalado, fue resultado de un problema intraétnico más que una estrategia de vinculación nacional. Alicia Barabás menciona que el territorio pasa a ser simbólico o sagrado y, por tanto etnoterritorio, cuando se construye a partir de procesos históricos de articulación entre naturaleza y sociedad en específicos contextos de interacción, de tal manera que son concebidos como "espacios poseídos por poderosas entidades anímicas territoriales, llamadas dueños, señores, padres o reyes de lugares: dueño del cerro o del monte, de la tierra, de los animales, del agua, del viento, del rayo, entre otros" (Barabás, 2008: 122-123).

Para el caso que aquí nos ocupa el territorio puede concebirse como etnoterritorio, ya que justamente existen distintos lugares de referencia relacionados con aspectos míticos fundacionales, con episodios calificados como milagrosos o con sitios considerados "pesados", en tanto son habitados por alguna deidad que reclama un comportamiento específico. Estos sitios sagrados encapsulan un tiempo y un lugar que perviven en la memoria de las personas más allá del territorio material. Estos lugares Bakhtin (1981: 7) los describe como cronotopos, es decir:

[...] puntos en la geografía de una comunidad donde el tiempo y el espacio se cruzan y fusionan. El tiempo adquiere carne y se hace visible para la contemplación humana; asimismo, el espacio se carga y responde a los movimientos del tiempo y la historia y al carácter perdurable de un pueblo [...] Los cronotopos se erigen así como monumentos a la comunidad misma, como símbolos de ella, como fuerzas que actúan para dar forma a las imágenes de sí mismas a sus miembros. ${ }^{6}$

Distintos cerros que conforman la serranía de SPL están asociados a la sacralidad zapoteca; el principal es el que conocemos como cerro del Encanto, lugar asociado al rayo, pues se cree que éste habita el lugar. Desde la década de 1960 el investigador Gabriel de Cicco hacía alusión al carácter sagrado del Encanto:

De acuerdo con las leyendas [el cerro del Encanto] fue morada de los dioses cuando todavía vivían en la tierra. Se dice que los dioses todavía viven allí en forma de espíritus y que la montaña, todavía fértil, produce en sus laderas plantas y frutas maravillosas. Según los indígenas del pueblo de [San Jerónimo] Coatlán, si una familia quiere ir de peregrinación al "Cerro Encantado", sólo necesita llevar sus tortillas ya que todos los frutos de la tierra se dan allí naturalmente. Pero si esta familia se lleva a su casa estos comestibles del cerro, se les convierten en culebras (De Cicco, 1963: 173-174).

\footnotetext{
${ }^{6}$ Traducción libre del autor.
} 
Al ser morada del rayo este cerro es sagrado y es el que ocupa el primer plano del lienzo de San Jerónimo Coatlán, por tanto, hay muchas actividades que no pueden realizarse en dicha zona, especialmente la caza de venados, puesto que éstos junto con las culebras y lagartijas son de su propiedad. Una historia que cuentan los abuelos se refiere a este vínculo entre el rayo y el venado:

Dicen que hace mucho tiempo vivía un señor allá por el encanto, allá tenía su ranchito. Ese señor se dedicaba a cazar venados. También sembraba su maíz y con eso se mantenía. Pero un día que andaba matando venados se le apareció el rayo y le dijo: ¿por qué andas matando mi ganado? Ahora te voy a llevar a mi casa y te vamos a comer. Esos venados son míos y ya no quiero que los estés matando. Entonces el rayo se lo llevó a su cueva. El señor nomás lloraba y le pedía perdón al rayo, le decía que ya no iba a matar más venados. En eso estaban cuando llegaron los hijos del rayo, pero el rayo grande escondió al señor para que no lo vieron los rayos pequeños. Pero los hijos del rayo lo ventearon y le dijeron al rayo grande "aquí huele a gente, hay que comérnoslo". Entonces el rayo mayor les explicó a sus hijos sobre la historia de ese señor y les dijo que el señor estaba muy arrepentido y que ya no iba a matar más venados. Al final logró convencer a los rayos pequeños para que no se lo comieran, pero con la condición de que iban a tener al señor un tiempo ahí con ellos para vigilarlo y ver si de verdad estaba arrepentido. Entonces ahí estuvo el señor con los rayos, iban a sembrar maíz y aunque el señor veía a los venados no intentaba matarlos, así que después de un tiempo dijo el rayo mayor: este señor ya está listo para regresar a su casa y como ha demostrado que ya cambió, le vamos a ayudar. Mira -le dijo al señor -ten este bule, ahí hay mucha neblina; ahora te vas a dedicar a cosechar frutas y verduras. Para que riegues tus plantas solo tienes que abrir el bule para que llueva sobre tus tierras. Así le dijo y entonces el señor pudo regresar a su casa y desde entonces se dedicó a cosechar frutas y verduras. Dicen que entonces ese señor bajaba desde El Encanto y venía a estas rancherías a vender sus productos. Así fue como dejó de matar los venados.

El cerro del Encanto también es el sitio donde tradicionalmente cada año se acude a realizar la petición de las lluvias, dado que ahí es la morada del rayo, deidad asociada a la lluvia y la agricultura. Hasta hace algunas décadas la petición de las lluvias se realizaba mediante rituales de origen prehispánico dirigidas por un saurín, pero con la presencia cada vez más fuerte de la Iglesia, que "aunque no condena estas concepciones y prácticas (ritualidad mesoamericana), sí las transforma intencionalmente intentando suavizarlas y retocarlas" (Barabás, 2008: 127). De esta forma, en lo más alto del cerro del Encanto se construyó hace poco una capilla católica la cual curiosamente lleva el nombre de "El Señor del Encanto" donde anualmente se sigue llevando a cabo "la pedimenta", ahora encabezada por un sacerdote católico. 
El territorio también es sagrado y simbólico en tanto que se establece como lugar de unión entre la tierra y el hombre. Así, dos grandes rituales de nacimiento han fraguado esta relación: el primero es el contexto del hogar, el sitio donde uno nace y al cual se está unido mediante el enterramiento del cordón umbilical en alguno de los extremos de la casa, ${ }^{7}$ sucedido por la búsqueda del tonal, que recaerá en el primer animal que deje sus huellas en un camino de ceniza que rodea la casa. ${ }^{7}$ Así, el nuevo integrante no sólo estará unido al territorio, sino también a su animal, a su protector y protegido.

Un segundo ritual, por desgracia ya casi en desuso, es la presentación formal del infante al territorio después de los 40 días de nacido. Según relata el señor Galdino López, "el niño es presentado en un arroyo o en el río; ahí se deben lavar por primera vez sus ropas. Se ofrece humo de copal y veladoras y se presenta en un rezo al niño". En SPL ya no hay especialistas en dicho ritual, quienes se encargaban de llevar el conteo de los días para tales celebraciones. Por consiguiente, sobre esta concepción sagrada del territorio se construyeron diversos conocimientos comunitarios de distintas especializaciones. Las curanderas lograron identificar la causa de distintas enfermedades relacionadas con malas conductas en lugares sagrados. Al respecto platica la señora Soledad Ríos que cuando una persona pierde la movilidad de alguna de sus extremidades se debe a que su cuerpo ha sido poseído por el chaneque, un personaje travieso que habita los cerros y que se apodera del cuerpo de la persona con flojera; así pues, las curanderas lograron determinar esa relación y establecer la cura, que consiste básicamente en reprender al chaneque para que abandone el cuerpo del poseído. De esta manera:
[...] los sistemas indígenas de conocimiento están enraizados profundamente en la tierra, en la comunidad de relaciones totales, en los lugares concretos construidos social y culturalmente durante siglos o milenios. Lugares que tienen nombres y me- morias antiguas, paisajes de diálogos relacionales milenarios, de co-desarrollo de todos los organismos animales y vegetales, de todas las aguas, rocas, vientos y estre- llas, y de todos los entes simbólicos tangibles e intangibles que otorgan orden o provocan desequilibrio en la vida o en la muerte (Varesse, 2011: 119).

Baste esta breve alusión a la construcción simbólica y sagrada del territorio en Soledad Piedra Larga para presumir que se trataba de un pueblo que encontraba en el territorio prácticamente todo lo necesario para vivir bien. Además, tal como está documentado en Pérez (2019b), el territorio como fuente de las epistemologías indígenas locales constituía el espacio de aprendizaje por tradición, de modo que, como veremos más adelante, no era necesaria una escuela rural federal, pues la escuela rudimentaria cumplía con aquello que los

\footnotetext{
${ }^{7}$ Testimonio del señor Zótero Pérez.
} 
pobladores consideraban necesario en este tiempo y en ese lugar, o sea, la lectura y la escritura, incluso la oralidad en castellano.

\section{Persistencia de la escuela rudimentaria en SPL (1930-1965)}

Quizá una de las razones externas por las que no se instaló una escuela rural federal en SPL, sea que la nueva comunidad era muy pequeña, apenas conformada por unas cuantas familias, pues recordemos que para entonces la mayoría vivía en rancherías. Empero, los comuneros se organizaron para construir su propia escuela gestionada de forma autónoma, donde ellos mismos contrataron un maestro municipal que atendiera a los pocos alumnos. Así, la mayoría de los maestros eran comuneros de San Jerónimo Coatlán, que habían sido alfabetizados y castellanizados por la escuela rural mexicana en esa localidad. Lamentablemente quienes fungieron como maestros municipales ya fallecieron, por tanto quedará la incógnita acerca de sus percepciones al respecto.

Para 1940 las distintas geografías del estado de Oaxaca marcaban la distribución de los maestros, ya que "estaban divididos en cuatro categorías: los federalizados, la mayoría en zonas urbanas y semiurbanas; los federales, ubicados en zonas rurales; algunos en las escuelas Artículo 123, pagados por las empresas; había pocos maestros municipales" (Sigüenza, 2015: 142).

Sobre los maestros municipales hay escasa bibliografía, pero probablemente muchos de ellos fueron formados en alguna de las normales que para tal caso existían en la república. De acuerdo con Sigüenza (2015), aunque había pocos maestros municipales estos fueron contabilizados en 1940 mediante un mapa de las zonas escolares que el director de Educación Federal, profesor Luis Ramírez, solicitó a los inspectores escolares. Esto significa que aunque los maestros municipales eran pagados por los municipios, sus planes de estudio obedecían a las legislaciones oficiales. Pero en el caso de los maestros municipales de Soledad Piedra Larga al parecer era distinto. Por una parte, según dejan ver los relatos de los comuneros de mayor edad, los maestros de ese entonces "no eran maestros del gobierno" y tampoco habían estudiado en las normales; "eran gente de la comunidad de San Jerónimo que nomás sabían leer y escribir en la castilla”, ${ }^{2}$ además de que su labor consistía únicamente en enseñar a leer y escribir en español y realizar las operaciones matemáticas básicas, es decir, seguían la tradición de las escuelas rudimentarias, aunque esta categoría no es empleada entre los adultos de SPL.

\footnotetext{
${ }^{8}$ Testimonio de la señora Francisca López.
} 
Por tal razón, en la escuela rudimentaria de Piedra Larga no se implementaron las distintas corrientes pedagógicas que desde los años 30 y hasta 1965 hubo en el país, situación que también se observa en otras regiones marginadas de Oaxaca como algunas comunidades mixes donde persistieron las escuelas rudimentarias (Kraemer, 2003: 110) Así, la efímera escuela socialista del gobierno de Lázaro Cárdenas y la posterior escuela del amor, que comenzó durante la gestión de Manuel Ávila Camacho y se concretó con Miguel Alemán Valdés (1946-1952) (Meneses, 1988), no tuvieron presencia en esta comunidad, en tanto el "plan de once años" quizá se alcanzó medianamente. Recordemos que, por ejemplo, en 1957 hubo una reforma en los planes de estudio, el cual quedó organizado de la siguiente manera:

\begin{abstract}
I Materias instrumentales (los instrumentos propios para el manejo de las demás): lenguaje, aritmética y geometría. II Materias aptas para conocer y aprovechar la naturaleza (Se relacionan con los hechos y los fenómenos de la naturaleza inorgánica y viva y, sobre todo, del hombre), las ciencias naturales: física, química y biología (botánica, zoología, anatomía y fisiología humanas). III. Materias encaminadas al conocimiento y mejoramiento de la sociedad (implican las creaciones del espíritu humano y la organización, fines y resultados de la vida social): geografía e historia; y educación cívica y ética. La geografía ocupa un puesto intermedio o de enlace entre el grupo II y III, pues la geografía física pertenece al grupo de las ciencias naturales y la geografía humana, económica, social y política, corresponden a las ciencias de la cultura. IV Materias para conocer, encauzar, estimular y aprovechar, por medio de actividades específicas, las aptitudes de los alumnos: 1) educación física; 2) trabajos manuales (con la variedad de las labores relacionas con la vida del hogar, para las niñas); 3 ) dibujo y artes plásticas; y 4) música y canto (Meneses, 1988: 407-408).
\end{abstract}

Sin embargo, algunos señores de SPL que estudiaron primaria entre 1957 y 1965 comentan que en ese tiempo no se veían las materias de geografía, historia o ciencias naturales; tampoco había libros de texto de ningún tipo, salvo el silabario el cual era obligatorio aprendérselo de memoria. Además de eso, el maestro sólo atendía hasta cuarto grado. Para concluir los estudios de primaria el niño tenía que trasladarse a alguna escuela rural oficial, tal como se establecía en las escuelas rudimentarias de 1911.

El señor Aarón Pérez comentó haber estudiado dos años de primaria entre 1962 y 1963; sus maestros eran municipales, recuerda que uno de ellos se llamaba Eulogio y que era originario de San Sebastián Coatlán, un municipio zapoteco vecino de San Jerónimo Coatlán. Señaló también que la comunidad tenía una escuela de adobe y láminas de cartón, pero que no se utilizaba, pues su difunto abuelo, el señor Bernabé López, ofreció para tal fin una casa que tenía en buenas condiciones. El señor Zótero Pérez, padre de Aarón Pérez, señala que a los maestros municipales de SPL no les pagaba el municipio, sino la propia comunidad mediante cooperación que se realizaba entre todos los comuneros, independientemente de si 
tenían hijos en la escuela o no. Lo anterior concuerda con otros contextos mexicanos durante la primera mitad del siglo Xx en que el sostenimiento escolar corría por parte de las comunidades o ayuntamientos, tal es el caso de las escuelas en Tlaxcala referidos por Rockwell (2007b) y las escuelas en la Sierra Norte de Puebla documentado por Acevedo (2015).

Al parecer el sistema educativo comunitario en SPL no era oficial, pues ninguno de los comuneros entrevistados dijo haber obtenido algún documento oficial que certificara sus estudios. Al respecto, el señor Aarón señaló que al concluir el año escolar, el maestro les entregaba una boleta de prueba, que por sus características parece que se trata de una especie de examen final mediante el cual el niño debía demostrar los conocimientos adquiridos, de lo contrario tendría que repetir el año. Sin embargo, esta boleta de prueba era una instrumento aparentemente de uso personal del maestro, pues los niños más aventajados solían ayudar a calificar la prueba. Además, parece ser que la comunicación sobre la aprobación o reprobación del niño se le entregaba directamente al padre de familia.

Por otra parte, como ya anticipaba, el hecho de que la comunidad de spl estuviera de alguna manera al margen de las dinámicas nacionales obedece a factores tanto internos como externos. De los externos es posible advertir un olvido por parte del gobierno mexicano; olvido que responde, mas no se justifica, a la geografía del lugar que no brindaba ningún beneficio económico a un país en auge y proceso de industrialización. En este sentido, aunque el territorio municipal de San Jerónimo Coatlán es rico en recursos forestales, la industria maderera era débil en la década de 1930, cobrando relevancia nacional una década después mediante un decreto a la Ley Forestal de 1940 que permitía concesiones forestales a empresas privadas a través de Unidades Industriales de Explotación Forestal (UIEF), lo que permitió a la empresa papelera Fapatux obtener concesiones para explotar los bosques en distintas regiones de Oaxaca, entre ellos los bosques del municipio de San Jerónimo Coatlán en 1973 (Pérez, 2019a: 93). Hasta antes de la década de 1970 la población de Soledad Piedra Larga vivía prácticamente al margen del Estado. De hecho, los servicios básicos como la luz eléctrica llegaron muy tarde y hasta la fecha no se cuenta con alcantarillado, drenaje ni pavimentación. Las brechas de terracería que conectan a SPL con la cabecera municipal datan de la década de 1970; el agua potable y un centro de salud fueron instalados hasta la década del año 2000. La escuela rural federal se estableció hasta 1965, como se verá más adelante, mientras que la telesecundaria se inauguró en 1997. En realidad, las palabras del director de Educación Federal de Oaxaca, en 1940, refleja la perspectiva que se tenía de los pueblos originarios: "Los pueblos en que se hallan establecidas las escuelas, aunque tengan la categoría política de municipios, no son otra cosa, que humildes congregaciones de indígenas de raza indígena a donde nunca había llegado la acción de ningún gobierno; esos municipios están integrados por rancherías pobladas de gente que se halla viviendo aún la vida que vivían las tribus indígenas de los tiempos de la conquista" (cit. en Sigüenza, 2015: 147). 
Quizá esta desvinculación con la vida nacional se debe más a factores internos que encuentran una posible explicación en el fuerte vínculo con el territorio tanto instrumental como simbólico. Recordemos que hacia 1930 los comuneros habían sido capaces de acudir a instancias gubernamentales para fundar legalmente la comunidad, por lo que también pudieron haber hecho algo similar para solicitar maestros federales y escuela rural. En realidad, hasta la década de 1970 la comunidad de SPL permaneció casi al margen de la vida nacional. Durante esos tiempos - cuentan los abuelos - la actividad principal consistía en la agricultura para el autoconsumo, así como la caza, dado que en las serranías abundan venados, jabalíes, ardillas y armadillos, incluso una diversidad de aves comestibles como palomas, primaveras y gallinitas monteses. La hidrografía del lugar es abundante, por lo que los diversos ríos de la región (Atoyac, Rana, Leche, Tablas, etc.) también eran y son aprovechados para la pesca de camarón, chacal, cangrejos, ranas y peces. En aquellos años el trueque permitía el acceso a diversos productos, incluso algunos aperos de labranza podían conseguirse a cambio de café — producto que comenzó a ser comercializado en la región hacia 1960_, por lo que a decir de los pobladores prácticamente no se necesitaba dinero.

El extenso territorio instrumental era habitado de extremo a extremo, de modo que algunos comuneros señalan que caminaban hasta tres horas para llegar hasta SPL desde sus rancherías, así que muchos de ellos se quedaban semanas enteras en esta comunidad y volvían a sus ranchos los fines de semana, situación que influyó en la escasa escolarización, pues la mayoría sólo estudiaban uno o dos años. Los abuelos sostienen que para la década de 1950 existían al menos al menos 15 rancherías importantes pertenecientes a SPL: El Progreso, El Mirador, El Toreño, Tierra Blanca, Bugambilias, El Rosario, La Yerbasanta, Buena Vista, La Escalera, El Porvenir, Cerro Sol, Río Piedra, Río Rana, Piedras Negras, Río Salacua, además de otras menos importantes conocidas localmente con el nombre del propietario, por ejemplo: rancho de tio Camilo, rancho de tio Pedro, etcétera, todas ellas alejadas entre 45 minutos y más de tres horas a pie.

Los abuelos también mencionan que en tiempos de siembra y pisca del maíz el ausentismo escolar era muy alto; hasta la década de 1990 estas actividades, además de la pisca de café, entre diciembre y febrero, siguieron provocando ausentismo. Personalmente viví en un pequeño rancho cafetalero a finales de los años noventa, por lo que recuerdo que para llegar a la escuela caminaba una hora entre las montañas, así que junto con mi hermano me quedaba una semana en la comunidad viviendo con unos parientes y regresaba al rancho los fines de semana. En tiempos de lluvia solía ausentarme de la escuela semanas completas.

Cabe recalcar que la orografía de SJC y de SPL se compone básicamente de serranías "caracterizadas por una topografía muy accidentada y altitudes que van de los 1,000 a los 2,700 msnm. En la zona se encuentra una gran cantidad de barrancas y cañadas con 
riachuelos, la mayoría de ellos permanentes" (Campos y Villaseñor, 1995: 97), siendo el cerro del Encanto el punto más alto; incluso los cerros con mayor altitud en Oaxaca se localizan en la Sierra Sur (ver mapa 1). Los riachuelos y arroyos que riegan prácticamente todos los rincones del territorio permitían a los pobladores vivir de una manera incluso seminómada; algunas abuelas recuerdan que en distintas épocas del año se trasladaban durante meses a otros sitios, como La Cumbre o El Encanto, donde sembraban maíz. En esos sitios acondicionaban cuevas y vivían ahí.

La siembra del sistema milpa que incluye maíz, frijol, chile, calabaza, ejotes y tomate, además de la recolección de yerbas silvestres y la caza del venado, proveía lo necesario para la subsistencia. Todas estas actividades también implicaban una relación muy estrecha con el territorio pues, como ya hemos señalado, la siembra del maíz incluía distintos rituales en etapas específicas del ciclo agrícola. La caza del venado también demandaba pedir permiso a los guardamontes, so castigo a quienes pasaran por alto el mandato (Pérez, 2019b). La recolección de yerbas comestibles también exigía un conocimiento sobre épocas del año y lugares de recolección. Por ejemplo, los hongos comestibles aparecen con las primeras lluvias, sobre todo, en tierra húmeda tapizada de resina de pino; el palo de chile se encuentra en los lugares más altos y fríos del territorio, o la flor de cuachepil, que se encuentra sólo en las copas de los árboles del mismo nombre.

El territorio entonces se entiende no únicamente como un espacio simbólico (Barabás, 2004) sino también de sobrevivencia, de ahí la alusión a la madre Tierra, pues también provee cobijo y comida. En ese tiempo tampoco había energía eléctrica, así que se aprovechaba el ocote, una conífera que produce una sustancia viscosa conocida como trementina, altamente inflamable, capaz de retener el fuego por mucho tiempo y resistente al viento. Las propias casas se construían con barro y madera; estas construcciones tradicionales se conocen como casas de mayute y a diferencia de las estructuras de adobe incluían delgadas varas atravesadas que las hacían más resistentes. Viviendo de ese modo los abuelos comentan que no tenían necesidad de salir de sus rancherías, solamente viajaban de vez en cuando a Nopala, un pueblo más grande, ubicado en la región chatina, donde acudían a comprar aperos de labranza, sal y materiales industriales que se comenzaron a introducir en la época.

En suma se puede afirmar que desde 1930 hasta 1970 la comunidad de Soledad Piedra Larga fue capaz de vivir prácticamente al margen de las dinámicas nacionales, debido a que el territorio les ofrecía todo lo necesario para poder vivir. La vida en el cerro marcaba las dinámicas comunitarias, éste les enseñaba todo lo que necesitaban conocer para la vida. La escuela no era necesaria más que para continuar el proceso de apropiación de la nueva lengua, ahora en el plano de lectura y la escritura, pero no como un elemento que les brindara "otras oportunidades de vida", como actualmente al gunos padres de familia esperan de la escuela para sus hijos. 


\section{La escuela rural federal en Soledad Piedra Larga}

Todo parece indicar que la escuela rural federal llegó a Soledad Piedra Larga hasta 1965 y aunque no se encontraron documentos oficiales en SPL que así lo demuestren, se confirma mediante los relatos orales de los comuneros nacidos entre 1950 y 1960. Por ejemplo, el señor Aarón Pérez, nacido en 1955, menciona que cuando tenía 8 años (en 1963), le tocaron maestros municipales y posteriormente tomó clases con un maestro federal, muy probablemente el primero en llegar a SPL, Ilamado Miguel, a quien describe como un maestro "muy bravo" que propinaba sendos reglazos en las manos. El maestro Miguel venía de otro estado de la república lo cual concuerda con los maestros rurales federales de aquella época.

El testimonio del señor José Ríos, nacido en 1958, comprueba la hipótesis de que los maestros rurales llegaron en 1965, ya que él refiere que en su primer año de clases le tocó un maestro municipal pero luego le tocó con uno federal, aunque no recuerda su nombre. Quizá fue el mismo maestro Miguel. Otros comuneros como Hilario López —ahora vecino de Cuautla, Morelos - también tomó clases con el maestro Miguel, lo mismo que Cesáreo López, Amado Pérez y otros más nacidos a mediados de 1950. Por su parte, Soledad Ríos, nacida en 1962, comentó que a ella ya no le tocaron los maestros municipales, pues cuando comenzó a ir a la escuela, en 1968, ya había maestros federales. Pascacio Pérez, nacido en 1963, también coincide en que a ellos ya no les tocaron los maestros municipales; en este caso, mencionó el nombre de dos de sus maestros: Elena y Gabriel quienes tampoco eran de Oaxaca.

No obstante la llegada de la escuela rural federal, ésta no cambió mucho las dinámicas comunitarias, pues varias personas de la comunidad sostienen que entre 1960 y 1970 seguían viviendo en la ranchería La Escalera y asistían a la escuela a veces cada semana y a veces todos los días. Mencionan que en ese tiempo a casi nadie le gustaba ir a la escuela sobre todo por la lejanía, pero como la escolaridad era obligatoria tenían que ir, de lo contrario había multas para los padres de familia.

Las dinámicas de la comunidad continuaron hasta mediados de la década de 1970, particularmente hasta 1973, cuando un fenómeno externo modificó profundamente la relación sagrada con el territorio. Hasta entonces, como he señalado, las comunidades tuvieron un manejo y control total de territorio, pero ese año la empresa papelera Fapatux logró obtener una concesión para trabajar los bosques que hasta ese momento seguían vírgenes. Quienes llegaron a ver los inmensos pinos que había antes de la llegada de la papelera aseguran que eran tan gruesos que para rodearlos se necesitaban hasta 10 personas con los brazos extendidos; recuerdan que eran altísimos de hasta 40 y 50 metros de altura, lo cual no es aventurado considerando que "la empresa Fapatux durante los primeros diez años de concesión logró producir anualmente 120 mil m³ de madera de primera clase" (Pérez, 2019a: 96). 


\section{La perspectiva escolar en la actualidad}

A partir de la década de 1970 y con más fuerza entre 1990 y el 2000 las dinámicas comunitarias se modificaron notablemente. Las actividades tradicionales como la caza y la agricultura fueron sustituidas por el aprovechamiento forestal. Se hizo cada vez más necesaria la escolarización debido a las nuevas tendencias socioeconómicas donde las comunidades entraron en intensa relación con la vida social nacional.

Entre el 2000 y el 2010 se abandonaron paulatinamente todas las rancherías menores debido a que en esa década las plantaciones de café, última actividad que los convocaba a vivir en los cerros, sufrieron daños irreparables a causa de las plagas que afectaron la región. Durante un trabajo de campo, en junio de 2018, visité distintas rancherías abandonadas, todas ellas están destruidas y la naturaleza ha invadido aquellos lugares que antes eran bellas casas de adobe. El llamado "aprovechamiento forestal” sustituyó a las plantaciones de café como actividad económica principal entre los pobladores, de manera que hoy en día esta actividad convoca a jóvenes y adultos por igual. Cabe resaltar que las nuevas escolarizaciones tampoco lograron desprender la relación hombre-comunidad, pues he observado una capacidad de agencia en relación con la escuela, ya que muchos jóvenes que habían pasado por la experiencia escolar comenzaron a servir mediante el sistema de cargos en puestos de secretarios, tesoreros, ayudantes municipales, incluso representantes municipales. En este sentido se aprecia el papel de los comuneros por seguir otorgando a la experiencia escolar un sentido comunitario.

Los comuneros perciben la escuela como un espacio que de ser aprovechado puede resultar en beneficio para la comunidad. Comentan que si hay personas preparadas, éstas pueden contribuir a sacar adelante al pueblo, lo cual deja ver una perspectiva social y comunitaria de la escolaridad, contrario a la perspectiva individual que se observa en muchas ocasiones, donde el éxito escolar se ve como éxito personal y se traduce en el deseo de obtener bienes materiales personales. Desde luego que esta idea también está presente entre los deseos de los jóvenes de nuestras comunidades, pero estos deseos también convergen con la intención de mejorar las condiciones de la localidad.

Esta idea de la escuela como un elemento de fortalecimiento comunitario también se observa en el hecho de que la comunidad procura la mejor infraestructura de la escuela, anteponiendo el cuidado de las aulas a muchas otras necesidades del pueblo; así lo deja ver la siguiente nota de mi diario de campo que describe una asamblea comunitaria en Las Palmas, comunidad vecina de Soledad Piedra Larga la cual se dedicó a discutir el gasto anual, mismo que se destinó en su mayor parte a una obra escolar: 
Hoy 22 de abril se llevó a cabo una Asamblea de comuneros en Las Palmas, para tratar "asuntos relacionados con el bienestar y progreso de la comunidad". Recibí un citatorio donde me invitaron a la reunión. El asunto principal consistió en acordar el uso de un recurso económico aprobado para la gestión 2018 en la localidad. Dicho recurso era de 1 millón 650 mil pesos. En la asamblea se decidió ocupar una parte del dinero para apoyar a la ranchería Junta de los Ríos, para que pudieran tener agua potable, ya que un grupo de habitantes de dicha ranchería acudieron ante la Asamblea de Las Palmas para que los apoyaran, pues argumentan que en tiempo de seca sufren de sequía. Luego de una discusión de más de una hora se decidió apoyarlos. El monto de esta obra sería de 900 mil pesos, por lo que Las Palmas aceptó contribuir con el $50 \%$ de los gastos, mientras que la otra mitad la saldaría la comunidad de El Progreso. De esta manera el presupuesto para Las Palmas quedó en 1 millón, 200 mil pesos, habría que decidir en qué utilizar el dinero, así que hubo las siguientes propuestas:

- Pavimentación de una calle

- Alcantarillado de la telesecundaria

- Construcción de un puente

Tras una hora de debate la Asamblea acordó por unanimidad que la prioridad de ese año sería el alcantarillado de la telesecundaria, pues en tiempo de lluvias se inunda el terreno. Aquí cabe destacar cómo muchos comuneros a pesar de no tener hijos estudiando en la telesecundaria consideraron que eso era la prioridad. Incluso por ahí se escuchó una voz "hay que invertir en la educación, pues". Otro más comentó "no le hace que se gaste toda la feria en el alcantarillado, hay que darle prioridad". 9

Lo anterior permite ver que la comunidad ha logrado hacer de la escuela un espacio de relevancia social, lo cual también está documentado en otros contextos sociales con presencia de escuelas rurales, tal como se observa en comunidades mazahuas del estado de México, "A través de su presencia regular y participando en actividades que mantienen y celebran la vida escolar, los miembros de la comunidad se convierten en agentes activos que crean experiencias de educación culturalmente relevantes para sus hijos. Al mismo tiempo, integran sus escuelas en la vida social de sus comunidades (Paradise y Robles, 2016: 61).

\section{Conclusiones}

A partir de la experiencia concreta en la comunidad de Soledad Piedra Larga se observa que los pueblos originarios poseen una capacidad de agencia respecto a su devenir histórico; cómo, a partir de sus dinámicas socioculturales e históricas, internas logran perfilar un tipo

${ }^{9}$ Diario de campo, 22 de abril de 2018, p. 45-46. 
de sociedad que refleja sus formas de vida tradicionales $y$, pese a que reciben elementos culturales ajenos como la escuela (Bonfil, 1991), son capaces de reconfigurarlas de acuerdo con sus propias lógicas. No se trata de sociedades victimizadas y sumisas a merced del sistema global.

Si bien las dinámicas globales terminan por afectar las dinámicas comunitarias, esto no sucede automáticamente, sino que se observan negociaciones y resistencias, incluso apropiaciones como sucedió con el español, lengua que se adquirió en SPL hacia 1930, pero cuyo uso obedeció al sistema cultural de la comunidad. Aunque la castellanización fue promovida por la escuela desde la década de 1910 vemos cómo en el caso de SPL se trató de una mera coincidencia con un problema étnico local. Esta experiencia también permite ver las tensiones entre los objetivos de las políticas de Estado y la forma en que realmente operan en el interior de las localidades.

Particularmente enfaticé que la escolarización no fue una necesidad comunitaria durante buena parte del siglo xx y es hasta finales del mismo cuando, debido a las nuevas dinámicas de relación con la sociedad nacional, la escuela comienza a tener otros sentidos aunque sin perder el objetivo comunitario. Así, la presencia de la escuela rudimentaria desde 1930 hasta 1965 puede verse como reflejo de una sociedad local que encontraba en sus formas de vida tradicionales, y en relación con el territorio sagrado, lo necesario para la vida, incluso para la buena vida. De ahí que la comunidad tampoco se haya movilizado en busca de los medios para hacerse de una escuela rural como mandaba la ley; recordemos que antes fueron capaces de acudir a instancias del gobierno para lograr la fundación oficial de su pueblo, lo cual quiere decir que sí tenían las condiciones para hacer lo propio respecto a la escuela. Aunado a lo anterior, el Estado tampoco tenía interés en invertir en la escolarización de una población que no resultaba atractiva para las políticas de modernización e industrialización del país, pues el territorio agreste en donde se asienta SPL apenas y es conocido; además, se sabe que desde el Porfiriato la mayor extensión del territorio oaxaqueño estuvo en manos de los pueblos, contrario al caso de estados del centro del país como Morelos, donde más de la mitad de las tierras estaban ocupadas por las haciendas (Falcón y Buve, 1988: 160). Es prudente destacar que aunque el territorio de SPL es rico en madera de pino, los proyectos forestales tomaron auge en México a partir de 1940 y, particularmente en el municipio de San Jerónimo Coatlán, hasta la década de 1970, por tanto hasta entonces ingresaron las empresas madereras.

En síntesis, considero que la falta de atención por parte del Estado junto con las formas de vida tradicionales con base en la territorialidad sagrada es lo que a mi juicio explica la presencia de una escuela que en teoría tuvo que haberse superado desde 1920. También sostengo que la capacidad de agencia de la población de SPL les permitió permanecer al margen de la vida nacional, dado que poseían las condiciones necesarias para prescindir 
del asistencialismo estatal. En contraste, actualmente y a partir de la presencia de las dinámicas capitalistas de la sociedad nacional se trata de una comunidad catalogada en pobreza extrema de acuerdo con el Consejo Nacional de Evaluación de la Política de Desarrollo Social (Coneval), lo que en última instancia incita a reflexionar en torno a las desigualdades sociales promovidas muchas veces por el propio Estado mexicano.

\section{Fuentes}

Archivos

Archivo de Bienes Comunales de San Jerónimo Coatlán, carpeta 1, Títulos Primordiales. Lienzo de San Jerónimo Coatlán.

Archivo de Bienes Comunales de San Jerónimo Coatlán, carpeta 1, Títulos Primordiales. Mapa de San Jerónimo Coatlán.

Archivo General de la Nación, Ciudad de México, folder Inquisición, vol. 37, exp. 9, Proceso del Santo Oficio de la Inquisición de México contra don Alonso, don Juan y don Andrés, caciques de Coatlán, por idolatras, 1544-1547.

Hemerografía

Acevedo, Ariadna (2015), "Entre el legado municipal y el avance del gobierno federal: las escuelas de la Sierra Norte de Puebla, 1922-1942", Relaciones. Estudios de Historia y Sociedad, vol. 36, núm. 143, pp. 51-84.

Barabás, Alicia (2004), "La construcción de etnoterritorios en las culturas indígenas de Oaxaca", Desacatos, núm 14, pp. 145-168.

Barabás, Alicia (2008), "Cosmovisiones y etnoterritorialidad en las culturas indígenas de Oaxaca", Antípoda, núm. 7, pp. 119-139.

Bonfil, Guillermo (1991), "La teoría del control cultural en el estudio de procesos étnicos", Papeles de la Casa Chata, año 2, núm. 3, pp. 165-204.

Campos, Álvaro y José L. Villaseñor (1995), "Estudio florístico de la porción central del Municipio de San Jerónimo Coatlán (Oaxaca)", Boletín de la Sociedad Botánica de México, núm. 56, pp. 95-120.

De Cicco, Gabriel (1963), "El lienzo de San Jerónimo Coatlán", Tlalocan, vol. 4, núm. 2, pp. 173-178.

Granja, Josefina (2010), "Procesos de escolarización en los inicios del siglo Xx. La instrucción rudimentaria en México", Perfiles Educativos, vol. XXXII, pp. 64-83.

Paradise, Ruth y Adriana Robles (2016), "Two Mazahua (Mexican) Communities: Introducing a Collective Orientation into Everyday School Life", Eurpean Journal of Psychology Education, núm. 31, pp. 61-77.

Pérez, Edgar (2018a), "Del di’zhke' al castellano: la apropiación lingüística en una comunidad zapoteca del sur de Oaxaca", Cuadernos del Sur, año 23, núm. 45, pp. 46-60.

Pérez, Edgar (2018b), "El lenguaje comunal como aproximación metodológica decolonial", Avá. Revista de Antropología, núm. 32, pp. 141-164.

Pérez, Edgar (2019a), "De pinos y motosierras: revisión crítica al aprovechamiento forestal comunal en San Jerónimo Coatlán, Oaxaca”, Polis. Revista Latinoamericana, núm. 52, pp. 92-105.

Pérez, Edgar (2019b), "Gué sant. Continuidad religiosa prehispánica entre los zapotecos del Sur de Oaxaca", Itinerarios. Revista de estudios lingüisticos, literarios, históricos y antropológicos, núm. 29, pp. 193-213. 
Rockwell, Elsie (2007a), "Huellas del pasado en las culturas escolares", Revista de Antropología Social, núm. 16, pp. 175-212.

Sigüenza, Salvador (2015), "El sistema educativo estatal y los primeros años de federalización educativa en la Sierra Norte de Oaxaca (1920-1942)", Relaciones, núm. 143, pp. 129-159

Varesse, Stefano (2011), "El dilema antropocéntrico. Notas sobre la economía política de la naturaleza en la cultura indígena", Quaderns de L'Institut Catalá d'Antropologia, núm. 27, pp. 97-122.

\section{Bibliografía}

Bakhtin, Mikhail (1981), The Dialogic Imagination: Four Essays, University of Texas Press, Austin. Tx.

Calderón, Marco (2018), Educación rural, experimentos sociales y Estado en México. 1910-1933, El Colegio de Michoacán, México.

Congreso Nacional de Educación Primaria (1911), Tipografía económica, México.

Falcón, Romana y Raymond Buve (1988), Don Porfirio presidente..., nunca omnipotente. Hallazgos, reflexiones y debates. 1867-1911, Universidad Iberoamericana, México.

Kraemer Bayer, Gabriel (2003), Autonomía indígena región mixe. Relaciones de poder y cultura política, Plaza y Valdés, Universidad Autónoma Chapingo, México.

Martínez, Jaime (2010), Eso que llaman comunalidad, Conaculta, Secretaría de Cultura del Gobierno del Estado de Oaxaca, México.

Meneses, Ernesto (1988), Tendencias educativas oficiales en México: 1934-1964. La problemática de la educación mexicana durante el régimen de Cárdenas y los cuatro siguientes, Universidad Iberoamericana, México.

Meneses, Ernesto (1998), Tendencias educativas oficiales en México, 1911-1934, Universidad Iberoamericana, México.

Necoechea, Gerardo (1996), "Un experimento en historia pública e historia oral: los museos comunitarios en Oaxaca", en Jorge Aceves (coord.), Historia oral. Ensayos y aportes de investigación, CIESAS, México, pp. 65-80.

Pani, Alberto (1912), La instrucción rudimentaria en la república, Secretaría de Instrucción Pública y Bellas Artes, México.

Pérez, Edgar (2014), A un siglo de distancia (1911-2011): semejanzas y diferencias de la educación microrural en México, Universidad Pedagógica Nacional, México.

Portelli, Alessandro (1991), "Lo que hace diferente a la historia oral", en William Moss, Alessandro Portelli y Ronald Fraser (coords.), La historia oral, Centro Editor de América Latina, Argentina, pp. 36-51.

Rockwell, Elsie (2007b), Hacer escuela, hacer estado. La educación pos-revolucionaria vista de Tlaxcala, Colegio de Michoacán, CIESAS, Cinvestav, México.

Roett, Riordan (1999), México y Estados Unidos. El manejo de la relación, Siglo XXI, México.

Rojas, Basilio (1958), Miahuatlán, un pueblo de México. Monografía del Distrito de Miahuatlán, Oaxaca, vol. I, Papeles de Oaxaca, México.

Rosas, Rodolfo (2016), "Quiegoqui. Un estado menézaa de la Sierra Sur de Oaxaca. Territorio, política y sociedad en el siglo XVI", tesis de licenciatura, Escuela Nacional de Antropología e Historia, México.

Santos, Boaventura (2010), Descolonizar el saber, reinventar el poder, Trilce, Extensión universitaria, Uruguay.

Solana, Fernando (2006), Educación: visiones y revisiones, Siglo XXI, México.

Torres Quintero, Gregorio (1913), La instrucción rudimentaria en la república, Museo Nacional de Arqueología, Historia y Etnología, México. 
Recursos electrónicos

Censo General de Población y Vivienda (1900), México. Disponible en: http://www.beta.inegi.org.mx/ app/biblioteca/ficha.html?upc=702825010018 (fecha de consulta: 21/2/2019).

INEGI (2004), La población hablante de lengua indígena de Oaxaca. Disponible en: http://internet.contenidos.inegi.org.mx/contenidos/productos/prod_serv/contenidos/espanol/bvinegi/productos/historicos/2104/702825497675/702825497675_5.pdf

INEGI (2010). "Censo de población y vivienda. Principales resultados por localidad (ITER)". Recuperado de: http://www.inegi.org.mx/est/contenidos/proyectos/ccpv/cpv2010/iter_2010.aspx el 10 de agosto de 2018.

Edgar Pérez Ríos. Maestro en Desarrollo Educativo por la UPN. Doctorando en Investigaciones Educativas en el Departamento de Investigaciones Educativas del CINVESTAV. Líneas de investigación: educación rural, educación comunitaria en Oaxaca, antropología de la educación entre los zapotecos de la Sierra Sur de Oaxaca. Últimas publicaciones: Edgar Pérez Ríos y Sinfuriano Olavarrri, "Prospectiva de la escuela primaria bilingüe "Moisés Sáenz" de San Mateo del Mar, Oaxaca", en Carrillo Antonio, María Zaldívar y Enrique Francisco (coords). Experiencias didácticas interculturales con la cultura ikoots. El caso de la Escuela Primaria Bilingüe "Moisés Sáenz" de San Mateo del Mar, Oaxaca, México, unAm, 2019, pp. 215228; Edgar Pérez Ríos, "Gué sant: continuidad religiosa prehispánica entre los zapotecos del Sur de Oaxaca", Itinerarios. Revista de estudios lingüísticos, literarios, históricos y antropológicos, núm. 29. Varsovia, Polonia: Universidad de Varsovia (en prensa).

Recibido: 13 de julio de 2019

Aceptado: 22 de octubre de 2019 